\title{
Can genetic research motivate parents to pursue genomic testing for children with autism spectrum disorder?
}

\author{
Augustus E Floyd and Lei $\mathrm{Xu}^{*}$
}

*Correspondence: xul14@ecu.edu

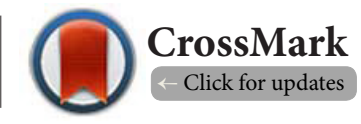

Department of Health Education and Promotion, College of Health and Human Performance, East Carolina University, Greenville, NC, 27858, USA.

\begin{abstract}
Advanced genomic tests such as Chromosomal Microarray Analysis (CMA) have been clinically offered to children with Autism Spectrum Disorder(ASD). However, the actual utilization of these tests is low among parents of children with ASD. The aim of this study is to examine the association between parental perceptions regarding autism research and their intention to take their children to undergo recommended genomic tests. We conducted a web-based survey using a community strategy in Eastern North Carolina among parents of children with ASD. Our final sample constituted 204 parents. The majority were mothers, married and Caucasian. Parents' test intention was high among this sample, and those desiring to help and expressing favorable perceptions toward ASD genetic research were more likely to test. Our findings suggest a link between parental attitudes towards genetic research and their decision to test a child with ASD. This study can influence patient education approaches of health professionals in counseling parental genetic testing decision, as well as informing policy creation about access and outreach for parents toward ASD research.
\end{abstract}

Keywords: Autism research, perceptions, parents of children with ASD, genetic tests

\section{Introduction}

Autism spectrum disorder (ASD) represents a range of neurodevelopmental conditions characterized by impairments in social communication, as well as repetitive and restricted interests or activities [1]. The manifestation of ASD usually occurs early in childhood and poses lifetime challenges to individuals on this spectrum. In recent years, ASD has become more widespread, thus making it an immediate public health concern [2]. According to the newest surveillance report by the Centers for Disease Control and Prevention, ASD affected one in every 68 children in the U.S. Although many parents of children might have concerns about their children's daily behaviors or social skills, the actual diagnosis of their children with ASD has thus far lagged behind [2].

Albeit the etiologies of ASD are not yet clearly identified, a substantial body of evidence has indicated the strong genetic basis of ASDs [1,3-5]. Several Chromosomal disorders such as Fragile $X$ and Down's Syndrome have also been identified as comorbid for ASD [6]. However, it is believed that roughly half of ASD genetic causes involve de novo, or non-syndromic, mutations [7]. Of these, 8-21\% of autism-linked genetic disor- ders exist in the form of a varying degree of point mutations known as copy number variants (CNVs) $[1,8]$. Genes that are considered CNVs for ASD can affect multiple points across numerous portions of the genome $[4,8]$. The variety of distances and number of CNVs might be associated with the complex range of phenotypes appearing on the autism spectrum $[1,3]$.

Chromosomal microarray analysis (CMA) has been reaffirmed by the 2013 revision guidelines of the American College of Medical Genetics (ACMG) as a first-tier genetic for children affected by neurodevelopmental disorders such as ASD $[5,7,9]$. The diagnostic yield of known ASD patients through CMA is found to be $15-20 \%$ in most studies, as well as almost $30 \%$ by prior screening on complex cases of ASD [6]. In this procedure, a blood sample is taken from the patient, and the genetic material is then comprehensively scanned in comparison to a healthy genome control $[10,11]$. In identifying distinct variants from the control, this reveals mutations that may be related to the development of ASD in the patient [9]. Obtaining a usable genetic diagnosis for autism is suggested to parents of affected children due to the possibility to influence treatment, management, and decision-making for family planning $[5,12,13]$. 
Floyd et al., Journal of Autism 2017,

http://www.hoajonline.com/journals/pdf/2054-992X-4-4.pdf

doi: 10.7243/2054-992X-4-4

In addition to its prospective uses for those receiving the test, another outcome of undergoing CMA for neurodevelopmental disorders is this information's potential role in advancing autism research $[4,5]$.

In the 2010 consensus statement of ACMG, the use of genomic databases was recommended to increase the utility of findings from genetic tests. One such example is DECIPHER Database of Chromosomal Imbalance and Phenotype in Humans Using Ensembl Resources) with the appropriate characters italicized hosted by the International Standard Cytogenic Array Consortium, which serves as an as online password-protected storage system of genetic tests results $[5,14]$. A more recent example that is specifically focused on autism genomic results is SFARI Gene 2.0 organized by the Simons Foundation [15]. Platforms such as these are designed to share and present data from genetic testing patients among researchers $[5,14,15]$. Professionals involved with this project can analyze a bank of test results recorded from patients to identify previously unidentified mutated genes which may contribute to the cause of ASD and other genetic disorders $[5,6]$. By identifying and recording new candidate genes, the genetic causes that underlie ASD can be more accurately described and better understood [16]. Thus far, the collection of this data has been useful in detecting and describing new CNVs, which can ultimately influence future diagnosis and treatment $[17,18]$. However further elucidation of suspected genetic components of ASD can only be driven by the contributions of results obtained from genetic testing data of affected individuals.

Biological parents are the usual primary caregivers of children suffering from ASD and thus the main rational actor in genetic testing decision-making for their children. When the phenotype of autism is diagnosed and is ruled to likely have an uncertain cause, genetic testing can be advised by a healthcare professional, typically the patient's pediatrician or a medical geneticist $[8, \mathbf{1 0}]$. Concerning the levels of parent interest, studies have consistently found that supportive attitudes to pursue genetic testing are high [19-22]. Despite positive perceptions as well as the potentially beneficial outcomes of a genetic diagnosis, actual utilization of CMA among other genetic testing options are reported as being low among parents of children with ASD [13,22-25].

One possible factor of intention toward receiving CMA testing is the prospect of contribution to the genomic databases used in research, such as SFARI Gene 2.0. Regarding this outcome of testing, decision by parents to have a biological offspring undergo CMA may represent a form of participation in autism genetic research. Parent perceptions toward using their ASD-affected child's information in genetic research have been previously been found to be overall positive [26]. Due to this information being passed on for study within a genomic resource for the use of researchers, electing to participate in research using CMA results can be considered an altruistic motivation. Throughout studies of autism genetic research, altruism is found as a consistent motivator $[\mathbf{2 0 , 2 6 , 2 7 ]}$. For the
Simon's Simplex Collection, it was discovered that at least two-thirds of parents participated to altruistically contribute to autism research [27]. Trottier et al. [20] found in an exploratory study that participation was motivated by an amalgam of both personal interest and altruism.

Previous studies have shown contributing to research motivates genetic testing intention among tests for a variety of conditions. Exploratory and pilot studies have identified interest in furthering research as among the primary reasons given for testing for genetic causes of sudden cardiac death, smoking susceptibility, deafness, and a variety of cancers [28-32]. For quantitative studies involving genetic tests for conditions including BRCA, Alzheimer's, and Pancreatitis, testing intention has previously been associated with wanting to help advance research [33-37]. Regarding genetic testing for a variety of psychiatric disorders, a questionnaire-based study also found that positive belief in genetic researchers to use this information to advance knowledge was also associated with participants' intention to undergo genetic testing [38]. Because desire to help with research motivates intention to test for other genetic disorders, this may also be true for intention regarding genetic tests for ASD. Despite this trend among other conditions of desireof assist genetic research as being a motivator, cross-sectional studies have recommended that each test be properly assessed for its own factors of motivation and parameters that determine parents' perceptions of testing $[39,40]$. To date, no available quantitative studies have measured the intention to test an ASD-affected child as it is associated with desire to help with research or perspectives about research.

Recently, several qualitative studies have been conducted to measure parents' intention in receiving genetic testing for ASD, two of which were hypothetical studies focused on CMA [21,41-43]. Each has included parents' responses that suggest an interest in testing based on an acknowledgement of its use in ASD genetic research and desire to help advance these efforts. In a sample performed on an underserved population, desire to help with research was among most prominent items mentioned $[42,43]$. While the impact of altruism to help advance research on ASD features as a reason that parents would test, the relationship between testing and this altruistic motivation has not been documented. Information is needed to fill the gap regarding the extent of this factor as a motivator for genetic testing intention among parents of children with ASD.

To better understand the relationship of desire to help with genetic research on autism and test intentionality, parents across Eastern North Carolina were surveyed about their perceptions. This sample was collected from the surrounding region from which $X u$ et al $[42,43]$ previously detected desire to help with research as a motivator for interest in testing among parents. This study sought to answer two questions:(1) Is interest in CMA genetic testing associated with parents' desire to contribute to autism research? (2) Does perception about the impact of testing on autism research relate to parents' $C M A$ intentionality? 


\section{Methodology}

\section{Participants}

Our participants were required to be the biological parents of at least one child with autism residing in Eastern North Carolina. Age was necessitated at 18 years old, however age of the child of the participants with ASD was not restricted. English literacy was also required to read and complete the survey.

\section{Design and recruitment}

This study was a component of a larger interactive online survey distributed by email. The survey was designed by a panel of experts using instruments found from questionnaire-based studies which previously measured genetic testing perceptions, motivators, and barriers. It was then revised based upon revision sessions among the panel and the suggestion of a focus group of parents of children with autism, which included 20 members who were one-on-one interviewed. The completed 44-item instrument was uploaded to the online survey platform Qualtrics for parents to complete through convenience sampling. The unique link to complete the study was distributed to parents of children with autism through email contact to advocacy organizations within the designated counties of Eastern North Carolina. The primary method for advertising this project was through online listing, social media presence, and personal contact. Also, an identical paper-andpencil based survey was hand-delivered to participants in the local community and schools. Participation and successful completion of the survey was incentivized by a $\$ 20$ Walmart gift card. The entire research protocol was approved by the institute review board of East Carolina University.

\section{Outcome variables}

Regarding the survey's sample, demographic factors were taken of the sample. These measures included race, gender, average age, household income, and level of education.

The primary outcome variable was based on whether the parent would hypothetically take the child to receive genetic testing, which was coded as the dependent variable. In the survey, participants (parents) were asked the likelihood of them with "testing their child for ASD if recommended by a healthcare professional. Responses were measured on a fourpoint Likert scale which ranged "A great deal," "Somewhat," "Slightly," and "Not at all." It was coded Yes (1) if a participant responded, "A great deal" or "Somewhat," and No (0) was entered if a participant responded "Slightly" or "Not at all."

The other outcome variables were parents' motivation and perceptions toward ASD genetic testing. These were coded as four dependent variables. For parents' motivation involving helping with ASD research, the section was prefaced with the instructions" Please check whether the following factors would affect your decision-making." The response item "desire to help with research" was included to represent research as a possible reason to pursue genetic testing. Responses were measured on a Likert Scale which ranged "Very likely,"
"Likely," 'Unlikely," and "Very "unlikely." It" was coded Yes (1) if a participant responded, "Very likely" or "Likely", and No (0) was entered if a participant responded "Unlikely" or "Very unlikely."

To evaluate parents' agreement with the statements about ASD genetic research, three items were included in the survey. The first measure was "Genetic testing can positively impact autism research. "The second stated: "Genetic Research improves my child's quality of life." The third was a negative perception about the personal outcomes of ASD genetic testing regarding ASD research which stated: "Genetic testing would only be beneficial for autism research" were measured on a four-point Likert scale "agree." For each statement, Yes (1) was coded if the participant answered, "strongly agree" or "agree"; a No (0) was coded recorded if the participant answered, "disagree" or "strongly disagree".

\section{Statistical analysis}

Frequency tables were used to measure the demographic variables of the sample. Fisher's exact test and odds ratio was used to compare outcome variables examined in this study. This was done to assess the association between intention to test and responses related to both desire to assist with ASD research and perceptions about genetic research. Analyses were conducted using SPSS Version 23.

\section{Results}

Descriptive statistics of the sample are presented in Table 1. A total of $204(\mathrm{~N}=204)$ participants completely responded

Table 1. Demographic Characteristics of Parents ( $N=204)$.

\begin{tabular}{lll}
\hline Characteristic & & Percentage \\
\hline Gender & Male & 11.87 \\
& Female & 88.7 \\
\hline Ethnicity & Caucasian & 74.5 \\
& Black/African American & 12.7 \\
& Native American & 7.4 \\
& Hispanic & 2.5 \\
& Other/Mixed & 2.9 \\
\hline Education Level & & \\
& Did not Finish High School & 2.5 \\
& High School or GED & 11.8 \\
& Associate's Degree or Some College & 45.6 \\
& Bachelor's Degree & 25.0 \\
& Master's or Professional Degree & 15.2 \\
\hline Income & & \\
\hline & $<\$ 20,000$ & 13.2 \\
& $\$ 25,000-\$ 39,999$ & 20.6 \\
& $\$ 40,000-\$ 59,999$ & 14.2 \\
& $\$ 60,000-\$ 75,000$ & 25.5 \\
& $>\$ 75,000$ & 1.0 \\
& Other & \\
\hline
\end{tabular}


Floyd et al., Journal of Autism 2017,

http://www.hoajonline.com/journals/pdf/2054-992X-4-4.pdf

to all questionnaire items related to this study, 181 female and 23 male. All were parents of children with autism living in Eastern North Carolina. Majority of the participants were Caucasian and female. Most had completed some college and had a family annual income level above $\$ 40,000$. About $84.3 \%$ of the parents reported that they would take their children to receive ASD genetic testing (Figure 1).

Figure 1 is a subset pie chart which displays the subdivision of those who desire to contribute to research within those who would likely test. The figure also provides an association between desire to help with research and likelihood to test their child $\left(p=0.032^{*}\right.$ ) as determined by Fisher's exact test as well as with an odds ratio of 2.62 .

The relationship between likelihood to test and perceptions about ASD research was measured in Table 2. The text of the item is displayed along with the outcome of Fisher's test as well as the odds ratio, which measured the number of times participants who responded they would seek testing were more likely to agree with the statement than to disagree. For perception about genetic testing benefiting autism research, this item was found significantly associated at $P$ value of 0.001 . The odds ratio was also found as being 13.0 times likely to agree than to disagree with the statement. For the relationship between decision to test a child and belief that autism genetic testing favorably impacts the child's quality of life, these two measures were also significantly associated with

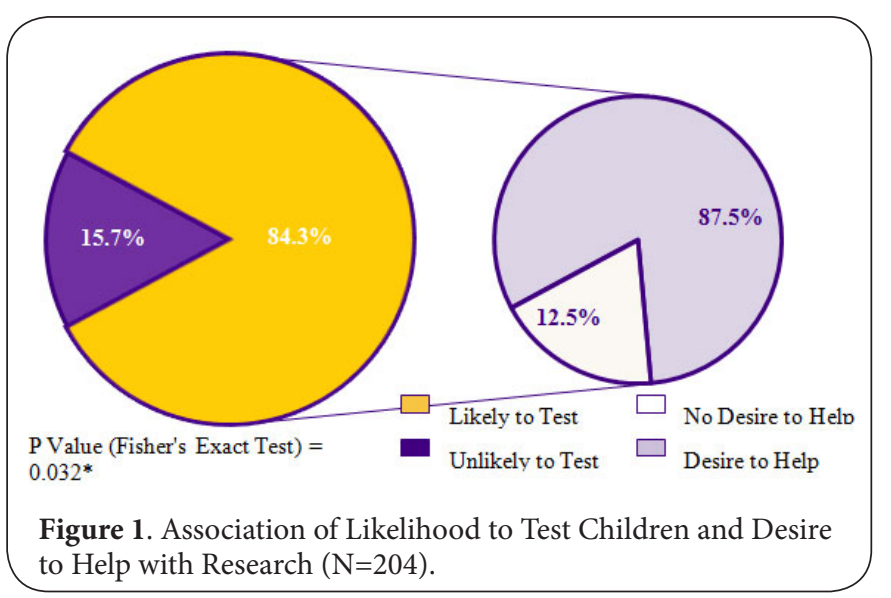

Table 2. Association of Likelihood to Test Children and Perceptions of Research ( $\mathrm{N}=204)$.

\begin{tabular}{lll}
\hline $\begin{array}{l}\text { Please check whether you agree or } \\
\text { disagree with the following statements: }\end{array}$ & P-value* & Odds ratio \\
$\begin{array}{l}\text { "Genetic testing can positively impact } \\
\begin{array}{l}\text { autism research" } \\
\text { "Genetic research improves my child's }\end{array}\end{array}$ & $0.001^{*}$ & 13.0 \\
$\begin{array}{l}\text { quality of life" } \\
\text { "Genetic testing would only be } \\
\text { beneficial for autism research, not me } \\
\text { or my family" }\end{array}$ & 0.340 & 0.676 \\
\hline
\end{tabular}

*By Fisher's Exact Test a p-value of 0.002 . The odds ratio was also measured at 3.63 times as likely to agree. Regarding parental belief that genetic testing would only beneficial to research, this result would not be significantly associated, with a p-value of .340. The odds ratio was found as being .676 times as likely to agree.

\section{Discussion}

This study provides insight about the possible decision making of parents of children with autism when pursuing genetic testing. The intention of parents within our study to have their children receive testing was found relatively high at $84.3 \%$, which suggests that majority of participants are likely to consider having their ASD-affected child undergo CMA. This number is consistent with existing findings about the level of parent interest toward ASD genetic testing [12,13,21,22,42]. For instance, Vande Wydeven et al. [24] found parental interest in utilizing genetic services at $90 \%$. The high intention to test measured in this study furthers the need to investigate factors that are considered important by parents related to testing decision, particularly for use in elucidating reasons for low CMA uptake in the clinical setting.

Most significantly, parental intention toward CMA genetic testing of their children within this study was associated with the prospect of contributing to research. This highlights that this factor, which has been consistently described in qualitative studies on parent perception about CMA could indeed be predictive of test intention $[21,41-43]$. The finding that increase in intention to test is associated with desire to support research corroborates existing data with similar findings from quantitative studies about genetic testing intention [33-35]. However, these studies represent findings on personal motivation for genetic testing rather than for that involving another family member, such as a biological child. While participants were not answering for a testing decision involving themselves, this provides further evidence of genetics research advancement as a motivator for genetic testing intention, these results represent the first quantitative findings for an ASD genetic test that considers research contribution as a factor of intention for genetic testing of a child.

Moreover, within this study, decision-making is also shown to be partly influenced by expectations about testing outcomes on ASD research. Data from this study partly supports statements made by parents of children with ASD in previous exploratory studies about CMA $[21,41]$. Intention increased with belief that genetic testing could advance ASD research, as was brought up by parents in existing studies [21,41-43]. Intention also increases with belief that assisting these efforts would improve their ASD child's "quality of life." It was hoped that research would offer their child additional support at some future point by parents that Reiff et al., [41] interviewed. However, negative attitudes about genetic testing for ASD, such as that testing outcomes would not be personally helpful, was challenged by lack of significance of this response item $[42,43]$. This data would suggest that greater parental 
belief and positive value of the outcomes concerning testing could serve as a motivator for testing intention. This would also indicate that negative perceptions about outcomes do not have a direct impact on hypothetical parental decision for genetic testing. It may be possible that parents being reluctant to support genetic research is associated with the medical usage or interventions pertaining to the test results. This also raised important concerns related to correct/accurate interpretation of the complicated genetic test results and how to make "actionable" treatment plan for the affected children.

Given that parents have indicated that genetic research is potentially a factor in test decision, health education studies have yet to explore possible value in affecting intention among parents. Enhancing knowledge and formation of beliefs on this subject may have a different effect on hypothetical testing decision beyond awareness. For this effort, it is necessary to implement educational interventions that can demonstrate the change of intention through providing information about research efforts via genetic testing for ASD.

\section{Conclusion}

The implications of this study inform existing data on parentalintention about genetic testing for ASD. Our results demonstrate an association between beliefs and motivations surrounding ASD research and testing decision, which at this point have not been assessed outside of qualitative findings. This study also elucidates that these factors related to genetic testing than are currently unconsidered regarding parents of ASD patients. Being able to describe their unique role and existence in regards to ASD genetic testing may help explain the paucity in research interest and actual involvement of parents. Such factors may also be experienced differently based upon social class and experience of the parent in question.

The possible outcomes of receiving positive information about research upon genetic testing intention are thus indicated by this study. Parents may wish to test their ASD-affected child at least partially because they want to advance research, because they perceive in genetic testing their child benefits research, or because they believe research developments enhance the prospects of their children. Conversely, this study demonstrates that negative perceptions about genetic research outcomes from testing, such as that they are not personally useful, do not impact testing intention of parents. This would indicate that negative assessments are not a significant factor in decision alongside positive assessments of outcomes related to genetic research. Since unfavorable perceptions can be neglected, it could thus be expected that providing information related to the role of genetic testing in ASD research would have a positive impact on testing intention of parents.

Especially because research contribution is an outcome not immediately experienced by parents in having their child undergo CMA, the worth of these findings is predicated on explaining this aspect of testing to parents. It could be recommended that current methods of patient education be modified to incorporate sufficient material about ASD research prospects. Health educators seeking to inform parents about genetic testing for ASD should include details within programs about the prospects of CMA to benefit DECIPHER, DGV, and other genomic resource endeavors within ASD research. In the clinical setting, both physicians and genetic counselors should consider the aspect of assisting genetic research within their support provided to parents of patients referred for advanced-level ASD genetic testing. By providing sufficient information about all considerations related to testing decision, professionals can more effectively direct their guidance and support offered to families about CMA. By supporting parental understanding of this endgame outcome for their child's procedure, this can be expected to increase their likelihood to pursue genetic testing. With greater awareness about this possibility, parents will be able to make a more informed decision about their utilization of genetic services and in doing so, potentially advance efforts to better understand ASD.

\section{Limitations}

Several factors limit the capabilities of this study's findings. First, due to the online nature of our survey and vast web-based advertisement medium through autism groups and organizations, we were not able to predict the accurate response rate of our study. Second, responses were under the self-reported data and assumption that respondents answered each question honestly and carefully to reflect their true beliefs. Third, parents provided responses from a hypothetical scenario of undergoing CMA genetic testing and may not represent a participant's views during actual testing experience. Fourth, although with our intention to recruit parents with low social economic, the study also did not produce a diverse sample as desired. Despite a higher area of income inequality and racial diversity within the area of recruitment, majority of active members of contacted parent organizations were considerably comprised of Caucasian mothers of mid-level SES. This may lower the generalizability of this study toward parents of minority backgrounds or lower SES.

\section{Competing interests}

The authors declare that they have no competing interests.

Authors' contributions

\begin{tabular}{|l|c|c|}
\hline Authors' contributions & AEF & LX \\
\hline Research concept and design & -- & $\checkmark$ \\
\hline Collection and/or assembly of data & $\checkmark$ & $\checkmark$ \\
\hline Data analysis and interpretation & $\checkmark$ & $\checkmark$ \\
\hline Writing the article & $\checkmark$ & -- \\
\hline Critical revision of the article & $\checkmark$ & $\checkmark$ \\
\hline Final approval of article & $\checkmark$ & $\checkmark$ \\
\hline
\end{tabular}

Acknowledgements

We want to thank the parents of children with ASD who 
Floyd et al., Journal of Autism 2017,

http://www.hoajonline.com/journals/pdf/2054-992X-4-4.pdf

doi: 10.7243/2054-992X-4-4

participated in our study as well as the autism parents' support groups/organizations, and public school teachers for their support with this study. This work was supported by a grant from the Simons Foundation (SFARI [award \#369023], [XL]).

Publication history

Editor: David Reiss, Imperial College London, UK.

Received: 25-May-2017 Final Revised: 16-Jun-2017

Accepted: 26-Jul-2017 Published: 08-Aug-2017

\section{References}

1. Heil KM and Schaaf CP. The genetics of Autism Spectrum Disorders-a guide for clinicians. Curr Psychiatry Rep. 2013; 15:334. | Article | PubMed

2. Centers for Disease Control and Prevention (CDC). Developmental Disabilities Monitoring Network Surveillance Year 2010 Principal Investigators. Prevalence of autism spectrum disorder among children aged 8 years - autism and developmental disabilities monitoring network, 11 sites, United States, 2010. MMWR Surveill Summ. 2014; 63:1-21.

3. Shen Y, Dies KA, Holm IA, Bridgemohan C, Sobeih MM, Caronna EB, Miller KJ, Frazier JA, Silverstein I, Picker J, Weissman L, Raffalli P and Jeste S. et al. Clinical genetic testing for patients with autism spectrum disorders. Pediatrics. 2010; 125:e727-35. | Article | PubMed Abstract | PubMed FullText

4. Schaefer GB and Mendelsohn NJ. Clinical genetics evaluation in identifying the etiology of autism spectrum disorders: 2013 guideline revisions. Genet Med. 2013; 15:399-407. | Article | PubMed

5. Miller DT, Adam MP, Aradhya S, Biesecker LG, Brothman AR, Carter NP, Church DM, Crolla JA, Eichler EE, Epstein CJ, Faucett WA, Feuk L and Friedman JM et al. Consensus statement: chromosomal microarray is a first-tier clinical diagnostic test for individuals with developmental disabilities or congenital anomalies. Am J Hum Genet. 2010; 86:749-64. | Article | PubMed Abstract | PubMed FullText

6. Shen J and Miller DT. Advances in Genetic Diagnosis of Autism Spectrum Disorders. Curr Pediatr Rep. 2014; 2:71-81.

7. Bauer SC and Msall ME. Genetic testing for autism spectrum disorders. Dev Disabil Res Rev. 2011; 17:3-8. | Article | PubMed

8. Carter MT and Scherer SW. Autism spectrum disorder in the genetics clinic: a review. Clin Genet. 2013; 83:399-407. | Article | PubMed

9. Toruner GA, Dermody J and Tolias P. Chromosomal microarrays: influential players in the diagnosis of developmental disorders. Pers Med. 2012; 9:167-169. | Article

10. Jiang YH, Wang Y, Xiu X, Choy KW, Pursley AN and Cheung SW. Genetic diagnosis of autism spectrum disorders: the opportunity and challenge in the genomics era. Crit Rev Clin Lab Sci. 2014; 51:249-62. | Article | PubMed

11. Tammimies K, Marshall CR, Walker $S$, Kaur G, Thiruvahindrapuram B, Lionel AC, Yuen RK, Uddin M, Roberts W, Weksberg R, Woodbury-Smith $M, Z$ waigenbaum L, Anagnostou E, Wang Z, Wei J and Howe JL et al. Molecular Diagnostic Yield of Chromosomal Microarray Analysis and Whole-Exome Sequencing in Children With Autism Spectrum Disorder. JAMA. 2015; 314:895-903. | Article | PubMed

12. McGrew SG, Peters BR, Crittendon JA and Veenstra-Vanderweele J. Diagnostic yield of chromosomal microarray analysis in an autism primary care practice: which guidelines to implement? J Autism Dev Disord. 2012; 42:1582-91. | Article | PubMed

13. Cuccaro ML, Czape K, Alessandri M, Lee J, Deppen AR, Bendik E, Dueker N, Nations L, Pericak-Vance M and Hahn S. Genetic testing and corresponding services among individuals with autism spectrum disorder (ASD). Am J Med Genet A. 2014; 164A:2592-600. | Article | PubMed

14. Firth HV, Richards SM, Bevan AP, Clayton S, Corpas M, Rajan D, Van Vooren S, Moreau Y, Pettett RM and Carter NP. DECIPHER: Database of Chromosomal Imbalance and Phenotype in Humans Using Ensembl
Resources. Am J Hum Genet. 2009; 84:524-33. | Article | PubMed Abstract | PubMed FullText

15. Abrahams BS, Arking DE, Campbell DB, Mefford HC, Morrow EM, Weiss LA, Menashe I, Wadkins T, Banerjee-Basu S and Packer A. SFARI Gene 2.0: a community-driven knowledgebase for the autism spectrum disorders (ASDs). Mol Autism. 2013; 4:36. | Article | PubMed Abstract | PubMed FullText

16. Asadollahi R, Oneda B, Joset $P$, Azzarello-Burri $S$, Bartholdi $D$, Steindl $K$, Vincent M, Cobilanschi J, Sticht H, Baldinger R, Reissmann R, Sudholt I, Thiel CT, Ekici AB, Reis A, Bijlsma EK, Andrieux J, Dieux A, FitzPatrick D, Ritter S, Baumer A, Latal B, Plecko B, Jenni OG and Rauch A. The clinical significance of small copy number variants in neurodevelopmental disorders. J Med Genet. 2014; 51:677-88. | Article | PubMed Abstract | PubMed FullText

17. Battaglia A, Doccini V, Bernardini L, Novelli A, Loddo S, Capalbo A, Filippi $\mathrm{T}$ and Carey JC. Confirmation of chromosomal microarray as a firsttier clinical diagnostic test for individuals with developmental delay, intellectual disability, autism spectrum disorders and dysmorphic features. Eur J Paediatr Neurol. 2013; 17:589-99. | Article | PubMed

18. Oikonomakis V, Kosma K, Mitrakos A, Sofocleous C, Pervanidou P, Syrmou A, Pampanos A, Psoni S, Fryssira H, Kanavakis E, Kitsiou-Tzeli S and Tzetis M. Recurrent copy number variations as risk factors for autism spectrum disorders: analysis of the clinical implications. Clin Genet. 2016; 89:708-18. | Article | PubMed

19. Narcisa V, Discenza M, Vaccari E, Rosen-Sheidley B, Hardan AY and Couchon $E$. Parental interest in a genetic risk assessment test for autism spectrum disorders. Clin Pediatr (Phila). 2013; 52:139-46. | Article | PubMed

20. Trottier M, Roberts W, Drmic I, Scherer SW, Weksberg R, Cytrynbaum $C$, Chitayat D, Shuman C and Miller FA. Parents' perspectives on participating in genetic research in autism. J Autism Dev Disord. 2013; 43:556-68. | Article | PubMed

21. Chen LS, Xu L, Huang TY and Dhar SU. Autism genetic testing: a qualitative study of awareness, attitudes, and experiences among parents of children with autism spectrum disorders. Genet Med. 2013; 15:274-81. | Article | PubMed

22. Amiet C, Couchon E, Carr K, Carayol J and Cohen D. Are there cultural differences in parental interest in early diagnosis and genetic risk assessment for autism spectrum disorder? Front Pediatr. 2014; 2:32. I Article | PubMed Abstract | PubMed FullText

23. Peabody J, DeMaria L, Tamandong-LaChica D, Florentino J, Acelajado $M C$ and Burgon T. Low Rates of Genetic Testing in Children With Developmental Delays, Intellectual Disability, and Autism Spectrum Disorders. Glob Pediatr Health. 2015; 2:2333794X15623717. | Article | PubMed Abstract | PubMed FullText

24. Vande Wydeven $\mathrm{K}$, Kwan A, Hardan AY and Bernstein JA. Underutilization of genetics services for autism: the importance of parental awareness and provider recommendation. J Genet Couns. 2012; 21:803-13. | Article I PubMed

25. Selkirk CG, McCarthy Veach P, Lian F, Schimmenti L and LeRoy BS. Parents' perceptions of autism spectrum disorder etiology and recurrence risk and effects of their perceptions on family planning: Recommendations for genetic counselors. J Genet Couns. 2009; 18:50719. | Article | PubMed

26. Johannessen J, Naerland T, Bloss C, Rietschel M, Strohmaier J, Gjevik E, Heiberg A, Djurovic $S$ and Andreassen OA. Parents' attitudes toward genetic research in autism spectrum disorder. Psychiatr Genet. 2016; 26:74-80. | Article | PubMed

27. Singh JS. Narratives of Participation in Autism Genetics Research. Sci Technol Human Values. 2015; 40:227-249.

28. Boudreault P, Baldwin EE, Fox M, Dutton L, Tullis L, Linden J, Kobayashi Y, Zhou J, Sinsheimer JS, Sininger Y, Grody WW and Palmer CG. Deaf adults' reasons for genetic testing depend on cultural affiliation: results from a prospective, longitudinal genetic counseling and testing study. J Deaf Stud Deaf Educ. 2010; 15:209-27. | Article | PubMed Abstract | PubMed FullText

29. Giordimaina AM, Sheldon JP and Petty EM. Anticipated motivation for 
genetic testing among smokers, nonsmokers, and former smokers: an exploratory qualitative study of decision making. Public Health Genomics. 2014; 17:228-39. | Article | PubMed

30. Hallowell N, Cooke S, Crawford G, Lucassen A, Parker M and Snowdon C. An investigation of patients' motivations for their participation in genetics-related research. J Med Ethics. 2010; 36:37-45. | Article | PubMed

31. Erskine KE, Hidayatallah NZ, Walsh CA, McDonald TV, Cohen L, Marion RW and Dolan SM. Motivation to pursue genetic testing in individuals with a personal or family history of cardiac events or sudden cardiac death. J Genet Couns. 2014; 23:849-59. | Article | PubMed Abstract | PubMed FullText

32. Esplen MJ, Madlensky L, Butler K, McKinnon W, Bapat B, Wong J, Aronson $\mathrm{M}$ and Gallinger S. Motivations and psychosocial impact of genetic testing for HNPCC. Am J Med Genet. 2001; 103:9-15. I PubMed

33. Roberts JS, LaRusse SA, Katzen H, Whitehouse PJ, Barber M, Post SG, Relkin N, Quaid K, Pietrzak RH, Cupples LA, Farrer LA, Brown T and Green $\mathrm{RC}$. Reasons for seeking genetic susceptibility testing among firstdegree relatives of people with Alzheimer disease. Alzheimer Dis Assoc Disord. 2003; 17:86-93. | Article | PubMed

34. Phillips KA, Warner E, Meschino WS, Hunter J, Abdolell M, Glendon G, Andrulis IL and Goodwin PJ. Perceptions of Ashkenazi Jewish breast cancer patients on genetic testing for mutations in BRCA1 and BRCA2. Clin Genet. 2000; 57:376-83. I Article I PubMed

35. Applebaum-Shapiro SE, Peters JA, O'Connell JA, Aston CE and Whitcomb DC. Motivations and concerns of patients with access to genetic testing for hereditary pancreatitis. Am J Gastroenterol. 2001; 96:1610-7. । Article | PubMed

36. Geller G, Doksum T, Bernhardt BA and Metz SA. Participation in breast cancer susceptibility testing protocols: influence of recruitment source, altruism, and family involvement on women's decisions. Cancer Epidemiol Biomarkers Prev. 1999; 8:377-83. | Article | PubMed

37. Tabor HK, Brazg T, Crouch J, Namey EE, Fullerton SM, Beskow LM and Wilfond BS. Parent perspectives on pediatric genetic research and implications for genotype-driven research recruitment. J Empir Res Hum Res Ethics. 2011; 6:41-52. | Article | PubMed Abstract | PubMed FullText

38. Laegsgaard MM, Kristensen AS and Mors O. Potential consumers' attitudes toward psychiatric genetic research and testing and factors influencing their intentions to test. Genet Test Mol Biomarkers. 2009; 13:57-65. | Article | PubMed

39. Etchegary $\mathrm{H}$. Public attitudes toward genetic risk testing and its role in healthcare. Per Med. 2014; 11:509-522.

40. Sweeny K, Ghane A, Legg AM, Huynh HP and Andrews SE. Predictors of genetic testing decisions: a systematic review and critique of the literature. J Genet Couns. 2014; 23:263-88. | Article | PubMed

41. Reiff M, Giarelli E, Bernhardt BA, Easley E, Spinner NB, Sankar PL and Mulchandani S. Parents' perceptions of the usefulness of chromosomal microarray analysis for children with autism spectrum disorders. J Autism Dev Disord. 2015; 45:3262-75. | Article | PubMed Abstract | PubMed FullText

42. Xu L, Mitchell LC, Richman AR and Clawson K. What Do Parents Think about Chromosomal Microarray Testing? A Qualitative Report from Parents of Children with Autism Spectrum Disorders. Autism Res Treat. 2016; 2016:6852539. | Article | PubMed Abstract | PubMed FullText

43. Xu L, Sun L, Mitchell LC, Richman AR and Floyd AE. Chromosomal Microarray Genetic Testing - A Qualitative Investigation among Parents of Children with Autism Spectrum Disorders in Rural North Carolina. J Clin Med Genomics. 2016; 4:143.

\section{Citation:}

Floyd $\mathrm{AE}$ and $\mathrm{Xu} \mathrm{L}$. Can genetic research motivate parents to pursue genomic testing for children with autism spectrum disorder? J Autism. 2017; 4:4.

http://dx.doi.org/10.7243/2054-992X-4-4 